\title{
Robustness of MULTIMOORA: A Method for Multi-Objective Optimization
}

\author{
Willem Karel M. BRAUERS ${ }^{1}$, Edmundas Kazimieras ZAVADSKAS ${ }^{2}$ \\ ${ }^{1}$ Faculty of Applied Economics, University of Antwerp \\ Prinsstraat 13, B2000 Antwerpen, Belgium \\ ${ }^{2}$ Institute of Internet and Intellectual Technologies, Vilnius Gediminas Technical University \\ Sauletekio al. 11, LT-10223, Vilnius, Lithuania \\ e-mail:willem.brauers@ua.ac.be,edmundas.zavadskas@vgtu.lt
}

Received: November 2011; accepted: February 2012

\begin{abstract}
Multi-Objective Optimization takes care of different objectives with the objectives keeping their own units. The internal mechanical solution of a Ratio System, producing dimensionless numbers, is preferred. The ratio system creates the opportunity to use a second approach: a Reference Point Theory, which uses the ratios of the ratio system. This overall theory is called MOORA (Multi-Objective Optimization by Ratio Analysis). The results are still more convincing if a Full Multiplicative Form is added forming MULTIMOORA. The control by three different approaches forms a guaranty for a solution being as non-subjective as possible. MULTIMOORA, tested after robustness, showed positive results.
\end{abstract}

Keywords: multi-objective optimization, robustness, ratio system, reference point method, full multiplicative form, MOORA, MULTIMOORA.

\section{Why Using Multiple Objectives Optimization}

Cost-Benefit Analysis is the traditional used method. Cost-Benefit takes a monetary unit as the common unit of measurement for benefits and costs. In this way, cost-benefit presents a materialistic approach, whereby for instance unemployment and health care are degraded to monetary items. Multi-Objective Optimization will take care of the disadvantages of Cost-Benefit: the objectives can keep their own units.

In order to define an objective better we have to focus on the notion of attribute. Keeney and Raiffa (1993, pp. 32-38) present the example of the objective "reduce sulfur dioxide emissions" to be measured by the attribute "tons of sulfur dioxide emitted per year". An attribute should always be measurable. Simultaneously we aim to satisfy multiple objectives, whereas several alternative solutions or projects are possible, characterized by several attributes. An alternative should be quantitatively well defined. An attribute is a common characteristic of each alternative such as its economic, social, cultural or ecological significance, whereas an objective consists in the optimization (maximization or minimization) of an attribute.

Economic Welfare (the term was invented by professor Pigou, 1920) comprises microand macroeconomics. Microeconomics would include attributes such as: yearly capacity 
to be reached, Net Present Value (NPV), Internal Rate of Return (IRR) and Payback Period. Macro-economics would include increase in Gross Domestic Product (GDP), surplus in the current account of the balance of payments, direct and indirect employment increase and ENPV. Indirect employment is measured by input-output techniques. ENPV means Economic Net Present Value, i.e., discounted revenues before national taxes, minus discounted investments, exclusive of subsidies. ENPV is different from GDP, but represents in macro-economics the counterpart of NPV, also with deduction of investments.

Satisfaction of all stakeholders is still another series of objectives. Stakeholders mean everybody interested in a certain issue. Due to consumer sovereignty and the economic law of decreasing marginal utility, consumer surplus, level of salaries, leisure time and again employment at the local and national level have to be taken into consideration.

Some attributes like NPV, ENPV, GDP, balance of payments surplus and consumer surplus are expressed in money terms, like dollars or Euros. However, a Euro in consumer surplus cannot be compensated for instance with a GDP-Euro. In addition, IRR is expressed in a percentage, the payback period in months or years, employment in number of persons per year, production, for instance in tons, etc. Consequently, a serious problem of normalization is present.

Well-being goes farther than Economic Welfare. In the well-being economy, each individual would have to feel good concerning material wealth, entrance to the most essential free goods like water supply, health, life expectancy at birth, education, all kind of security and concerning the environment. With other words, multiple objectives have to be fulfilled.

Well-being "tout court" concerns the well- being of the actual generation. Sustainable or Durable Development means well-being not only for the actual generation but also for the future generations. Indeed: development indicates time. "Developing countries" means developing over time. After the dictionary sustainable means capable of being maintained. In this way the KIJOTO agreement is sustainable development accentuated mainly on $\mathrm{CO}_{2}$ emissions.

Normalization means reduction to a normal or standard state. However, the term got many interpretations but the stress is mainly put on the unification of diverting systems of measurement. As decision making is interested in measurement, normalization in technology is a main starting point, whereas scales of measurement and measurement of quality may be troublesome (for more on normalization, see Brauers (2007).

\section{Conditions of Robustness in Multi-Objective Methods}

For the researcher in multi-objective decision support systems the choice between many methods is not very easy. Indeed numerous theories were developed since the forerunners: Condorcet (the Condorcet Paradox, against binary comparisons, 1785, LVIII), Gossen (law of decreasing marginal utility, 1853) Minkowski (Reference Point, 1896, 1911) and Pareto (Pareto Optimum and Indifference Curves analysis 1906, 1927) and 
pioneers like Kendall (ordinal scales, since 1948), Miller and Starr (Multiplicative Form, 1964), Roy et al. (ELECTRE, since 1966), Hwang and Yoon (TOPSIS, 1981), Brans et al. (PROMETHEE since 1984), Saaty (AHP, since 1988), Opricovic and Tzeng (VIKOR, 2004), Brauers (MOORA, 2004a, 2004b, 2004c) and Brauers and Zavadskas (MULTIMOORA, 2010b).

We intended to assist the researcher with some guidelines for an effective choice on basis of a definition of Robustness towards Multi-Objective Optimization. Elsewhere we tried to define robustness in relation to statistics and econometrics (Brauers and Zavadskas, 2010a).

By 1953, which is quite recent for statistics (as well known, statistics already existed in Roman times with the census of population), robust became a statistical term as "strong, healthy, sufficiently tough to withstand life's adversities" (Stigler et al., 1973, p. 872). Nevertheless, already in 1969, statistician Huber (1969) considered robustness as purely cardinal: as a compromise between a normal distribution and its light deviations. At a later time many statisticians or econometricians gave a sometimes different cardinal meaning to robustness (Brauers and Zavadskas, 2010a).

At the other side, we observe a move to a more vague and qualitative definition of robustness, namely to the meaning of common language (Webster's new Universal Unabridged Dictionary: robust: strong; stronger, strongest), from a cardinal towards a qualitative scale: the most robust one, more robust than ..., as robust as ..., robust, weak robust, less robust than ..., not robust etc., comparable to so many other scales in multiobjective analysis (for instance mentioned by Brauers (2004a, pp. 97-99).

Kreps (1990) esteems that robust predictions are crucial although the meaning given to robustness may depend on the context (also Vincke, 1999, 186(2)).

Concluding on the remark that significance of robustness depends on the context can be specified in different ways. First, robustness can be considered as cardinal or as qualitative. Second, if robustness is indicated as vague or arbitrary is it also not the case with inference statistics (Hoel, 1971, 2 versus Hays, 1974, p. 47; Casella and Berger, 2002, VII), probability theory (Hays, 1974, p. 47) and statistical specification (Intriligator, 1978, p. 2; Matyas and Sevestre, 1992, Chapter 9, versus Thomas, 1985, p. 71; Wonnacott, 1970, p. 312)? Third, robustness is characterized by completeness being present in the statistical population, when defined as covering events and opinions which are present, as well as in the statistical universe with events and opinions not only present but also possible (Brauers and Zavadskas, 2010a). Consequently, this completeness of robustness justifies also the making of a link with Multi-Objective Methods.

The most robust multi-objective method has to satisfy the following conditions (Brauers and Ginevicius, 2009, pp. 121-122).

1. The method of multiple objectives in which all stakeholders are involved is more robust than this one with only one decision maker or different decision makers defending their own limited number of objectives. All stakeholders mean everybody interested in a certain issue. Consequently, the method of multiple objectives has to take into consideration Consumer Sovereignty. The method taking into consideration consumer sovereignty is more robust than this one which does not respect consumer sovereignty. Community indifference loci measure consumer sovereignty. 
Solutions have to deliver points inside the zone of the highest possible community indifference locus.

2. The method of multiple objectives in which all non-correlated objectives are considered is more robust than this one considering only a limited number of objectives.

3. The method of multiple objectives in which all interrelations between objectives and alternatives are taken into consideration at the same time is more robust than this one with interrelations only examined two by two.

4. The method of multiple objectives which is non-subjective is more robust than this one which uses subjective estimations for the choice and importance of the objectives and for normalization.

4.1. For the choice of the objectives.

A complete set of representative and robust objectives is found after Brain Storming and Ameliorated Nominal Group Technique Sessions with all the stakeholders concerned or with representatives (The Ameliorated Nominal Group Technique is explained in Brauers and Zavadskas (2010c, pp. 72-74).

4.2. For giving importance to an objective.

With weights and scores importance of objectives is mixed with normalization. On the contrary Delphi can determine the importance of objectives separately from normalization. In addition, as all stakeholders concerned are involved, the Delphi Method is non-subjective (the Delphi Method is explained in Brauers and Zavadskas (2010c, pp. 74-75).

4.3. For normalization.

The method of multiple objectives which does not need external normalization is more robust than this one which needs a subjective external normalization. Consequently, the method of multiple objectives which uses nonsubjective dimensionless measures without normalization is more robust than this one which uses subjective weights (weights were already introduced by Churchman et al. (1957) and Churchman and Ackoff (1954) or subjective non-additive scores like in the traditional reference point theory (Brauers, 2004a, pp. 158-159).

5. The method of multiple objectives based on cardinal numbers is more robust than this one based on ordinal numbers: "an ordinal number is one that indicates order or position in a series, like first, second, etc." (Kendall and Gibbons, 1990, p. 1). Robustness of cardinal numbers is based first on the saying of Arrow (1974, p. 256): "Obviously, a cardinal utility implies an ordinal preference but not vice versa" and second on the fact that the four essential operations of arithmetic: adding, subtracting, multiplication and division are only reserved for cardinal numbers.

6. The method of multiple objectives which uses the last recent available data as a base is more robust than this one based on earlier data.

7. Once the previous six conditions fulfilled the use of two different methods of multiobjective optimization is more robust than the use of a single method; the use of three methods is more robust than the use of two, etc. 
Table 1

Comparative performance of some MODM methods

\begin{tabular}{llllll}
\hline MODM & $\begin{array}{l}\text { Computational } \\
\text { time }\end{array}$ & Simplicity & $\begin{array}{l}\text { Mathematical } \\
\text { calculations }\end{array}$ & Stability & $\begin{array}{l}\text { Information } \\
\text { type }\end{array}$ \\
\hline MOORA & Very less & Very simple & Minimum & Good & Quantitative \\
AHP & Very high & Very critical & Maximum & Poor & Mixed \\
TOPSIS & Moderate & Moderately critical & Moderate & Medium & Quantitative \\
VIKOR & Less & Simple & Moderate & Medium & Quantitative \\
ELECTRE & High & Moderately critical & Moderate & Medium & Mixed \\
PROMETHEE & High & Moderately critical & Moderate & Medium & Mixed \\
\hline
\end{tabular}

Consequently we have to find a method which satisfies all conditions, inclusive the seventh condition. It is the case with MOORA (Multi-Objective Optimization by Ratio Analysis). MOORA, eventually assisted with the Ameliorated Nominal Group Technique and with Delphi, is indeed composed of two methods: a Ratio System and a Reference Point Approach. MOORA will be explained in detail later.

The tests were made as non-subjective as possible, but as the authors of this article were involved in setting up the test, it seemed better to avoid any impression of favoritism. Therefore Chakraborty (2011, p. 1165), as an outsider, could judge better about MOORA. Chakraborty took up conditions of robustness and checked six famous methods of MultiObjective Decision Making for decision making in manufacturing. Table 1 shows the results.

Instead of "complete aggregation" Schärlig $(1985,1996)$ defines ELECTRE (ELECTRE I: Roy, 1968; ELECTRE II: Roy and Bertier, 1971; Fuzzy ELECTRE III: Roy, 1977; ELECTRE IV, without weights, Roy and Hugonnard, 1981) and PROMETHEE (Brans et al., 1984, 1986) as partial aggregations. In this way conditions two and three of robustness are not satisfied.

In addition, AHP (Saaty, 1988), ELECTRE and PROMETHEE are less robust after the 7 conditions as being based on binary comparisons. Even worse they lead to a Condorcet Paradox. Condorcet (1785) demonstrated the nonsense of binary comparisons for multifarious conclusions.

We use a Condorcet example after replacing the different rankings of candidates by different rankings of alternatives per objective, whereas scores per objective replace the numbers of votes.

The algorithm finally consists of a multifarious generalization of binary comparisons between possible alternatives facing several objectives. This algorithm could lead to a contradictory outcome as illustrated by the following example.

Alternatives A and B receive scores of the stakeholders for the realization of five objectives: 


$\begin{array}{lllllll}\text { Objectives } & & 1 & 2 & 3 & 4 & 5 \\ \text { Scores } & & \text { 23 } & 17 & 2 & 10 & 8 \\ \text { Ranking } & \text { 1st } & \text { A } & \text { B } & \text { B } & \text { A } & \text { B } \\ & \text { 2nd } & \text { B } & \text { A } & \text { A } & \text { B } & \text { A }\end{array}$

A P B (P means preferred to) with A scoring 33 against a preference for B of 27.

If however three alternatives are present, the outcome could be contradictory. Indeed:

$\begin{array}{lllllll}\text { Objectives } & & 1 & 2 & 3 & 4 & 5 \\ \text { Scores } & & 23 & 17 & 2 & 10 & 8 \\ \text { Ranking } & \text { 1st } & \text { A } & \text { B } & \text { B } & \text { C } & \text { C } \\ & \text { 2nd } & \text { B } & \text { C } & \text { A } & \text { A } & \text { B } \\ & \text { 3rd } & \text { C } & \text { A } & \text { C } & \text { B } & \text { A }\end{array}$

A P B P C with A scoring 23, B 19 and C 18.

Binary comparisons would have produced:

Between A and B: A (with 33) P B (with 27)

Between $\mathrm{C}$ and A: C (with 35) P A (with 25)

Between B and C: B (with 42) P C (with 18).

This is Contradictory indeed.

For Bordes and Tideman (1991, pp. 182-183) Arrow's General Possibility Theorem (Arrow, 1963, p. 13, 15, 97), which is rather an Impossibility Theorem, is mainly based on the manipulation of candidacies in voting, for us alternatives. The result could be a reverse order. Let us give an example for consistency conditions concerning two alternatives A and $\mathrm{B}$ :

$\begin{array}{lllll}\text { Objectives } & & 1 & 2 & 3 \\ \text { Scores } & & 9 & 7 & 4 \\ \text { Ranking } & \text { 1st } & \text { A } & \text { B } & \text { B } \\ & \text { 2nd } & \text { B } & \text { A } & \text { A }\end{array}$

B (with 11) P A (with 9). Suppose a third alternative is introduced, viz., C, in such a manner that:

$\begin{array}{lllll}\text { Objectives } & & 1 & 2 & 3 \\ \text { Scores } & & 9 & 7 & 4 \\ \text { Ranking } & \text { 1st } & \text { A } & \text { B } & \text { C } \\ & \text { 2nd } & \text { B } & \text { A } & \text { B } \\ & \text { 3rd } & \text { C } & \text { C } & \text { A }\end{array}$

leading to: A (with 9) P B (with 7) P C (with 4), i.e., a Reverse Order compared to the binary case. In this way the introduction of $\mathrm{C}$ could be a maneuver. Indeed Bordes and Tideman remark that for public works projects with two alternatives the legislative branch may favor B. If the executive branch prefers rather A, it will introduce a new project C, for which it does not care, but which will insure that A is chosen above B. 
TOPSIS (Hwang and Yoon, 1981) is less robust after the 7 conditions by violating condition one on Consumer Sovereignty. Elsewhere it is demonstrated that by following Euclidean distances TOPSIS deviate from the real ranking (Brauers, 2008).

Finally, VIKOR (Opricovic and Tzeng, 2004) is less robust after the 7 conditions by violating condition one on Consumer Sovereignty. Elsewhere it is demonstrated that by following Rectangular distances VIKOR deviate from the real ranking (Brauers, 2008). In addition, VIKOR still uses weights whereas Normalization is no more needed. Dimensionless figures do not need normalization anymore.

\section{The Data Assembled in a Matrix}

A table (a matrix) assembles the data with vertically numerous objectives, criteria (a weaker form of objectives) or indicators and horizontally alternative solutions like projects (Table 2)

The data originate from statistics, desk research, Project Engineering (UNIDO, 1978, pp. 98-128) or from simulated figures. In this way, alternatives, solutions or projects enter the response matrix as rows. Concerning projects information has to be as intensive as possible.

The question remains how to find and how to decide on the choice of the objectives. One decision maker like a captain of industry will focus on his own objectives. Different decision makers do not change the picture. In some industrial countries the large companies are obliged to have some directors from outside the company in the board of directors. Even this group of decision making will stick to its own limited objectives. Rather all stakeholders, which mean all persons interested in a certain issue, have to be found.

Once agreement reached about alternatives and objectives, a decision has to be taken how to read the Response Matrix, either horizontally or vertically.

\subsection{Horizontal Reading of the Response Matrix}

The Additive Weighting Procedure (MacCrimmon, 1968, pp. 29-33), which was called SAW, Simple Additive Weighting Method, by Hwang and Yoon (1981, p. 99) and Usual

Table 2

Matrix of responses

\begin{tabular}{lllllll}
\hline & Obj. 1 & Obj. 2 & $\ldots$ & Obj. $i$ & $\ldots$ & Obj. $n$ \\
\hline Alternative 1 & $\mathrm{X}_{11}$ & $\mathrm{X}_{21}$ & $\ldots$ & $\mathrm{X}_{i 1}$ & $\ldots$ & $\mathrm{X}_{n 1}$ \\
Alternative 2 & $\mathrm{X}_{12}$ & $\mathrm{X}_{22}$ & $\ldots$ & $\mathrm{X}_{i 2}$ & $\ldots$ & $\mathrm{X}_{n 2}$ \\
$\ldots$ & $\mathrm{X} \ldots$ & $\mathrm{X}_{\ldots}$ & $\ldots$ & $\mathrm{X}_{\ldots}$ & $\ldots$ & $\mathrm{X}_{\ldots}$ \\
Alternative $j$ & $\mathrm{X}_{1 j}$ & $\mathrm{X}_{2 j}$ & $\ldots$ & $\mathrm{X}_{i j}$ & $\ldots$ & $\mathrm{X}_{n j}$ \\
$\ldots$ & $\mathrm{X}_{\ldots}$ & $\mathrm{X} \ldots$ & $\ldots$ & $\mathrm{X} \ldots$ & $\ldots$ & $\mathrm{X} \ldots$ \\
Alternative $m$ & $\mathrm{X}_{1 m}$ & $\mathrm{X}_{2 m}$ & $\ldots$ & $\mathrm{X}_{i m}$ & $\ldots$ & $\mathrm{X}_{n m}$ \\
\hline
\end{tabular}




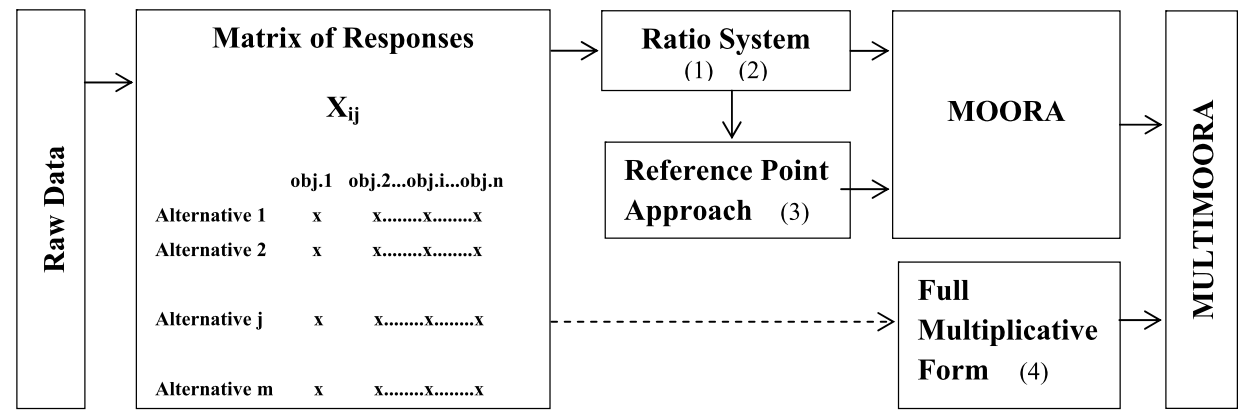

Fig. 1. Diagram of MULTIMOORA.

Reference Point Methods read the response matrix in a horizontal way. As the weights add to one a new super-objective is created and consequently it gets difficult to speak of multiple objectives.

Usual Reference Point Theory is non-linear, whereas non-additive scores replace the weights. The non-additive scores take care of normalization. But being non-additive the comments on the weights adding to one and consequently creating a super-objective is absent here.

With weights and scores importance of objectives is mixed with normalization. Indeed weights and scores are mixtures of normalization of different units and of importance coefficients.

\subsection{Vertical Reading of the Response Matrix}

Vertical reading of the Response Matrix means that normalization is not needed as each column is expressed in the same unit. In addition if each column is translated in ratios dimensionless measures can be created and the columns become comparable to each other. Indeed they are no more expressed in a unit. Different kind of ratios are possible but Brauers and Zavadskas (2006) proved that the best one is based on the square root in the denominator. The Ratio System which forms the basis of the MOORA method follows the vertical reading of the matrix. Figure 1 shows the exact relation between the two methods of MOORA and in addition to MULTIMOORA, MOORA plus the Full Multiplicative Form, to be explained later.

\section{Multi-Objective Optimization by Ratio Analysis (MOORA)}

\subsection{The Two Parts of MOORA}

The method starts with a matrix of responses of different alternatives on different objectives:

$$
\left(X_{i j}\right)
$$


with $x_{i j}$ as the response of alternative $j$ on objective $i ; i=1,2, \ldots, n$ as the objectives; $j=1,2, \ldots, m$ as the alternatives.

MOORA goes for a ratio system in which each response of an alternative on an objective is compared to a denominator, which is representative for all alternatives concerning that objective. For this denominator the square root of the sum of squares of each alternative per objective is chosen. Brauers and Zavadskas (2006) proved that this is the most robust choice:

$$
x_{i j}^{*}=\frac{x_{i j}}{\sqrt{\sum_{j=1}^{m} x_{i j}^{2}}}
$$

with $x_{i j}=$ response of alternative $j$ on objective $i ; j=1,2, \ldots, m ; m$ the number of alternatives; $i=1,2, \ldots n ; n$ the number of objectives; $x_{i j}^{*}=$ a dimensionless number representing the normalized response of alternative $j$ on objective $i$.

Dimensionless Numbers, having no specific unit of measurement, are obtained for instance by deduction, multiplication or division. The normalized responses of the alternatives on the objectives belong to the interval $[0 ; 1]$. However, sometimes the interval could be $[-1 ; 1]$. Indeed, for instance in the case of productivity growth some sectors, regions or countries may show a decrease instead of an increase in productivity, i.e., a negative dimensionless number.

For optimization these responses are added in case of maximization and subtracted in case of minimization:

$$
y_{j}^{*}=\sum_{i=1}^{i=g} x_{i j}^{*}-\sum_{i=g+1}^{i=n} x_{i j}^{*},
$$

with $i=1,2, \ldots, g$ as the objectives to be maximized; $i=g+1, g+2, \ldots, n$ as the objectives to be minimized; $y_{j}^{*}=$ the normalized assessment of alternative $j$ with respect to all objectives.

An ordinal ranking of the $y_{j}$ shows the final preference.

For the second part of MOORA the Reference Point Theory is chosen with the MinMax Metric of Tchebycheff as given by the following formula (Karlin and Studden, 1966, p. 280):

$$
\min _{(j)}\left\{\max _{(i)}\left|r_{i}-x_{i j}^{*}\right|\right\}
$$

with $\left|r_{i}-x_{i j}^{*}\right|$ the absolute value if $x_{i j}^{*}$ is larger than $r_{i}$ for instance by minimization.

This reference point theory starts from the already normalized ratios as defined in the MOORA method, namely formula (1). Preference is given to a reference point possessing as co-ordinates the dominating co-ordinates per attribute of the candidate alternatives and which is designated as the Maximal Objective Reference Point. This approach is called realistic and non-subjective as the co-ordinates, which are selected for the reference point, are realized in one of the candidate alternatives. The alternatives A $(10 ; 100), \mathrm{B}(100 ; 20)$ and C $(50 ; 50)$ will result in the maximal criterion reference point $R_{m}(100 ; 100)$.

Given the composition of (3) the results are ranked in an ascending order. 


\subsection{The Importance Given to an Objective by the Attribution Method in MOORA}

It may look that one objective cannot be much more important than another one as all their ratios are smaller than one (see formula (1)) Nevertheless it may turn out to be necessary to stress that some objectives are more important than others. In order to give more importance to an objective its ratios could be multiplied with a Significance Coefficient.

In the Ratio System in order to give more importance to an objective its response on an alternative under the form of a dimensionless number could be multiplied with a Significance Coefficient:

$$
\ddot{y}_{j}^{*}=\sum_{i=1}^{i=g} s_{i} x_{i j}^{*}-\sum_{i=g+1}^{i=n} s_{i} x_{i j}^{*},
$$

with $i=1,2, \ldots, g$ as the objectives to be maximized; $i=g+1, g+2, \ldots, n$ as the objectives to be minimized; $s_{i}=$ the significance coefficient of objective $i$; $\ddot{y}_{j}^{*}=$ the total assessment with significance coefficients of alternative $j$ with respect to all objectives.

For the Reference Point Approach the place of the significance coefficient would be:

$$
\left|s_{i} r_{i}-s_{i} x_{i j}^{*}\right|
$$

The Attribution of Sub-Objectives represents another solution. Take the example of the purchase of fighter planes (Brauers, 2002). For economics, the objectives concerning the fighter planes are threefold: price, employment and balance of payments, but there is also military effectiveness. In order to give more importance to military defense, effectiveness is broken down in, for instance, the maximum speed, the power of the engines and the maximum range of the plane. Anyway, the Attribution Method is more refined than that a significance coefficient method could be as the attribution method succeeds in characterizing an objective better. For instance, for employment two sub-objectives replace a significance coefficient of two and in this way characterize the direct and indirect side of employment separately.

\section{MULTIMOORA}

In his book of 2004 Brauers (2004a) described the three parts of MULTIMOORA: (1) the Ratio System Approach, producing dimensionless ratios, (2) the Reference Point Approach, but still based on scores, (3) the Full Multiplicative Form. Some time later Brauers (2004b, 2004c) switched over to a Reference Point Approach with instead of scores uses the ratios found in the ratio system. In this way dimensionless measures were obtained again. The synthesis of the two approaches was called later: MOORA (Brauers and Zavadskas, 2006). In 2010 a third approach was added and MULTIMOORA was born (Brauers and Zavadskas, 2010b). Indeed, MULTIMOORA is composed of MOORA and of the Full Multiplicative Form of Multiple Objectives. Up till now no other approach is 
known satisfying the previous six conditions of robustness and including three or more methods, MULTIMOORA becomes the most robust system of multiple objectives optimization.

\subsection{MOORA}

MOORA (Multi-Objective Optimization by Ratio Analysis) was explained under point 4 above.

\subsection{The Full Multiplicative Form of Multiple Objectives}

\subsubsection{Multiplicative Forms}

Mathematical economics is familiar with the multiplicative models like in production functions (e.g., Cobb-Douglas and Input-Output formulas) and demand functions (Teekens and Koerts, 1972).

Allen (1957, p. 473) launched the "bilinear and quadratic form" as: $\sum_{r} \sum_{s} a_{r s} x_{r} y_{s}$, for us concerning weights and objectives but with interrelations only examined two by two.

For Keeney and Raiffa (1993, p. 234) besides additive utilities, a utility function may also include a multiplication of the attributes beside. The two dimensional $u(y, z)$ can then be expressed as a multilinear utility function. This representation mixes additive and multiplicative parts (Brauers, 2004a, p. 228).

For Keeney (1973, p. 110) the additive form is rather a limiting case of the multiplicative utility function, for us the SAW method as explained earlier in Section 3.1.

The danger exists that the multiplicative part becomes explosive. The multiplicative part of the equation would then dominate the additive part and finally would bias the results.

Considering these shortcomings, preference will be given to a method that is nonlinear, non-additive, does not use weights and does not require normalization. Such multiplicative form for multi-objectives was introduced by Miller and Starr (1969, pp. 237239) and further developed by Brauers (2004a, pp. 227-245).

The following $n$-power form for multi-objectives is called from now on a FullMultiplicative Form in order to distinguish it from the above mentioned mixed forms:

$$
U_{j}=\prod_{i=1}^{n} x_{i j}
$$

with $j=1,2, \ldots, m ; m$ the number of alternatives; $i=1,2, \ldots, n ; n$ being the number of objectives; $x_{i j}=$ response of alternative $j$ on objective $i ; U_{j}=$ overall utility of alternative $j$.

The overall utilities $\left(U_{j}\right)$, obtained by multiplication of different units of measurement, become dimensionless. The outcome of this presentation is nonlinear, which presents an advantage, as the utility function of human behavior toward several objectives has to be considered as nonlinear. 


\subsubsection{How to Designate the Importance of an Objective in the Full Multiplicative \\ Form?}

Stressing the importance of an objective can be done by adding an $\alpha$-term or by allocating a coefficient (a Significance Coefficient) on condition that this is done with unanimity or at least with a strong convergence in opinion of all the stakeholders concerned.

In fact formula (4) has to run as follows:

$$
U_{j}=\prod_{i=1}^{n}\left(\alpha_{i}+\beta_{i} x_{i j}\right)
$$

with $j=1,2, \ldots, m ; m$ the number of alternatives; $i=1,2, \ldots, n ; n$ being the number of attributes and objectives; $x_{i j}=$ response of alternative $j$ on attribute $i$ of objective $i ; \alpha$ and $\beta$ are measures of importance; $U_{j}=$ overall utility of alternative $j . U_{j}$ is a dimensionless indicator.

Several situations may occur, related to the $\alpha$-terms and the $\beta$-coefficients.

1. All $\beta$-coefficients are larger than zero with all $\alpha$-terms equal to zero.

If three attributes and two alternatives are assumed:

$$
n=3, \quad m=2 \text {. }
$$

(a) in general: $\alpha_{1}=\alpha_{2}=\alpha_{3}=0$

$$
\begin{aligned}
& U_{1}=\beta_{1} \beta_{2} \beta_{3} x_{11} x_{21} x_{31}, \\
& U_{2}=\beta_{1} \beta_{2} \beta_{3} x_{12} x_{22} x_{32}
\end{aligned}
$$

(b) the $\beta$-coefficients have the form of weights:

$$
0 \leqslant \beta_{1} \leqslant 1, \quad 0 \leqslant \beta_{2} \leqslant 1, \quad \beta_{3}=1-\beta_{1}-\beta_{2},
$$

with the following outcome:

$$
\begin{aligned}
& U_{1}=\beta_{1} \beta_{2}\left(1-\beta_{1}-\beta_{2}\right) x_{11} x_{21} x_{31} \\
& U_{2}=\beta_{1} \beta_{2}\left(1-\beta_{1}-\beta_{2}\right) x_{12} x_{22} x_{32}
\end{aligned}
$$

(c) the $\beta$-coefficients have the form of ratios:

$$
\beta_{1}=1 / \gamma_{1}, \quad \beta_{2}=1 / \gamma_{2}, \quad \beta_{3}=1 / \gamma_{3},
$$

(these ratios have the form of weights if they satisfy the same conditions as under $b$ ).

$$
\begin{aligned}
& U_{1}=\left(1 / \gamma 1 / \gamma_{2} 1 / \gamma_{3}\right) x_{11} x_{21} x_{31} \\
& U_{2}=\left(1 / \gamma_{1} 1 / \gamma_{2} 1 / \gamma_{3}\right) x_{12} x_{22} x_{32}
\end{aligned}
$$




\section{Conclusion}

In the three cases, the relation between the two overall utilities remains the same:

$$
\frac{U_{1}}{U_{2}}=\frac{x_{11} x_{21} x_{31}}{x_{12} x_{22} x_{32}}
$$

The following conclusions arise from the invariance between the overall utilities.

\section{Rule I}

In the full-multiplicative form the relation between the utilities does not change if more importance is given to an objective by multiplying it by a factor. Indeed, at that moment all alternatives are multiplied with that factor.

\section{Consequence 1}

In the full-multiplicative form the introduction of weights is meaningless. Indeed weights are here in fact multiplying coefficients.

\section{Rule II}

Rule II implies that in the full-multiplicative form an attribute of an objective can be divided by a constant without changing the relation between the overall utilities of the alternatives.

\section{Consequence 2}

In the full-multiplicative form an attribute of the size $10,10^{2}, 10^{3}, 10^{6}, 10^{9}$ etc. can be replaced by the unit size without changing the relationship between the utilities of the alternatives.

This consequence is extremely important for attributes expressed in monetary units. Instead of expressing an attribute in tens, hundreds, thousands, millions, billions for instance of dollars, the use of one digit in the integer part is sufficient.

\section{General Conclusion}

A Beta Coefficient is senseless.

\section{An Illustrative Application}

The example in the Table 3 illustrates the theory. Three projects are competing in a firm having to maximize NPV (Net Present Value). At the same time, the government asks to maximize employment.

Table 3

Projects facing Multiple Objectives

\begin{tabular}{lll}
\hline & Increase of employment & NPV \\
\hline Project 1 & 400 man-years & $100 \mathrm{~m}$. Euro \\
Project 2 & 300 man-years & $150 \mathrm{~m}$. Euro \\
Project 3 & 100 man-years & $350 \mathrm{~m}$. Euro \\
\hline
\end{tabular}


1. All $\beta$-coefficients are equal to one and all $\alpha$-terms zero.

Applying Consequence 2 of Rule II the following outcome is obtained:

$$
\begin{aligned}
& U_{1}=4 \times 10=40, \\
& U_{2}=3 \times 15=45, \\
& U_{3}=1 \times 35=35, \\
& U_{2} P U_{1} P U_{3} .
\end{aligned}
$$

2. In addition to the previous case, assume that the stakeholders like to favor an attribute above the others. For instance, NPV is considered as valuable as two times the employment level $(\beta=2)$ :

$$
\begin{aligned}
& U_{1}=4 \times 2 \times 10=80, \\
& U_{2}=3 \times 2 \times 15=90, \\
& U_{3}=1 \times 2 \times 35=70, \\
& U_{2} P U_{1} P U_{3} .
\end{aligned}
$$

The outcome remains unchanged but with all utilities two times larger than in the previous case (Rule I). Additionally one could conclude that in the fullmultiplicative form the use of weights is senseless, as already mentioned in consequence 1.

3. By manipulating $\alpha$ the stakeholders like to favor an objective.

3a. Suppose the stakeholders like to favor the objective "increase in employment". Therefore they make $\alpha_{1}$ equal to 100 person-years with all $\beta$-coefficients remaining equal to 1 .

$$
\begin{aligned}
& U_{1}=5 \times 10=50 \\
& U_{2}=4 \times 15=60 \\
& U_{3}=2 \times 35=70 \\
& U_{3} P U_{2} P U_{1} .
\end{aligned}
$$

Unexpected not the employment objective is favored but rather the NPV objective under the form of $U_{3}$.

3b. Suppose the stakeholders like to stress the NPV importance by putting $\alpha_{2}$ equal to $600 \mathrm{~m}$. Euro with all $\beta$-coefficients remaining equal to 1 :

$$
\begin{aligned}
& U_{1}=4 \times 70=280, \\
& U_{2}=3 \times 75=225, \\
& U_{3}=1 \times 95=95, \\
& U_{1} P U_{2} P U_{3} .
\end{aligned}
$$

Unexpected not the NPV objective is favored but rather the employment objective under the form of $U_{1}$. 


\section{General Conclusion}

The use of an Alpha Coefficient is senseless.

Finally the solution remains by allocating an exponent to an objective.

\section{Attributes of Objectives Raised to Powers}

Allocating an exponent to an attribute of an objective signifies stressing the importance of this attribute.

Is consequence 2 of rule II also of application here? Miller and Starr (1969, pp. $237-$ 239) bring the answer. Table 4 demonstrates ratios that do not change if single-dollar units are transformed to million-dollar units even when attributes are raised to powers.

The costs, which are expressed in dollars, such as investment and labor costs, have to be minimized. The other objectives are minimized too: 0 for the best and 10 for the poorest (see Table 4).

1. An Incorrect Method that is Frequently used (Miller and Star, 1969, 238).

An additive method with the scores as weights gives different results by changing the scale:

(a) the dollar-attributes are expressed in unit dollars: $S 2 / S 1=1.50$

(b) in million dollars units instead of single-dollar units.

The sum of the products of the scores (here weights) with the strategies changes: $S 2 / S 1=1.38$.

The change in scale introduces dimensional distortion in the ratio.

2. A Dimensionally Correct Method:

(a) the dollar-attributes are expressed in unit dollars:

$$
\begin{aligned}
& S 1=(1,000,000)^{3}(6)^{4}(1.70)^{5}(7)^{1}(2)^{3}(9)^{2}=8.34 \times 1025, \\
& S 2=(1,500,000)^{3}(10)^{4}(1.50)^{5}(4)^{1}(8)^{3}(6)^{2}=1.89 \times 1028, \\
& \frac{S 2}{S 1}=\frac{1.89 \times 1028}{8.34 \times 1025}=226 .
\end{aligned}
$$

(b) in million dollars units:

$$
S 1=(1)^{3}(6)^{4}(1.70)^{5}(7)^{1}(2)^{3}(9)^{2}=8.34 \times 107,
$$

Table 4

Example of Multiple Objectives with Exponents

\begin{tabular}{lllll}
\hline Attributes & Units & Scores & Strategy $S 1$ & Strategy $S 2$ \\
\hline Investment & Dollars & 3 & $1,000,000$ & $1,500,000$ \\
Site & Preference* & 4 & 6 & 10 \\
Labor cost & Dollar/hour & 5 & 1.7 & 1.5 \\
Relations & Cooperation* & 1 & 7 & 4 \\
Raw-material & Quality* & 3 & 2 & 8 \\
Transport & Facility* & 2 & 9 & 6 \\
\hline
\end{tabular}

* 10 poorest; 0 best. 


$$
\begin{aligned}
& S 2=(1.5)^{3}(10)^{4}(1.50)^{5}(4)^{1}(8)^{3}(6)^{2}=1.89 \times 1010, \\
& \frac{S 2}{S 1}=\frac{1.89 \times 1010}{8.34 \times 107}=226 .
\end{aligned}
$$

$\mathrm{S} 1$ is preferred to $\mathrm{S} 2$ (a minimization process).

The ratios are indeed invariant to the transformation of scale. The indicator 226 is dimensionless. It certainly does not mean that $\mathrm{S} 1$ is 226-times better than $\mathrm{S} 2$.

\section{Conclusion}

Contrary to the $\beta$-coefficients or the $\alpha$ terms the introduction of exponents will influence the Ranking of the Alternatives.

Returning once again to the example of Table 3 point 1 , where the following ranking was obtained:

$$
\begin{aligned}
& U_{1}=4 \times 10=40, \\
& U_{2}=3 \times 15=45, \\
& U_{3}=1 \times 35=35, \\
& U_{2} P U_{1} P U_{3} .
\end{aligned}
$$

If an exponent 2 is given to N.P.V the ranking changes in favor of $U_{3}$ as was expected:

$$
\begin{aligned}
& U_{1}=\left(4 \times 10^{2}\right): 2=400: 2=200 \\
& U_{2}=\left(3 \times 15^{2}\right): 3=675: 3=225 \\
& U_{3}=\left(1 \times 35^{2}\right): 3.5=1225: 3.5=350 \\
& U_{3} P U_{2} P U_{1} .
\end{aligned}
$$

\section{Objectives Moving in a Different Direction}

How is it possible to combine a minimization problem with the maximization of the other objectives? Therefore, the objectives to be minimized are denominators in the formula:

$$
U_{j}^{\prime}=\frac{A_{j}}{B_{j}},
$$

with

$$
A_{j}=\prod_{g=1}^{i} x_{g i}
$$

$j=1,2, \ldots, m ; m$ the number of alternatives; $i=$ the number of objectives to be maximized, with

$$
B_{j}=\prod_{k=i+1}^{n} x_{k j},
$$


$n-i=$ the number of objectives to be minimized,

with $U_{j}^{\prime}$ : the utility of alternative $j$ with objectives to be maximized and objectives to be minimized.

It is true that the Full Multiplicative Form is read horizontally in the Response Matrix of Table 2. Nevertheless with the full-multiplicative form, the overall utilities, obtained by multiplication of different units of measurement, become dimensionless measures. This situation would not bias the outcomes amidst the several alternatives as the last ones are represented by dimensionally homogeneous equations, being: "formally independent of the choice of units" (De Jong, 1967, p. 28).

\section{The Theory of Dominance}

In the most of the not too complicated cases a summary of the ranking of the three MULTIMOORA methods is made. For very large matrices Brauers $e t$ al. developed a Theory of Dominance (Brauers and Zavadskas, 2011; Brauers et al., 2011).

\subsection{Axioms on Ordinal and Cardinal Scales}

1. A deduction of an Ordinal Scale, a ranking, from cardinal data is always possible (Arrow, 1974).

2. An Ordinal Scale can never produce a series of cardinal numbers (Arrow).

3. An Ordinal Scale of a certain kind, a ranking, can be translated in an ordinal scale of another kind.

In application of Axiom 3 we shall translate the ordinal scale of the three methods of MULTIMOORA in another one based on Dominance, being Dominated, Transitivity and Equability.

\subsection{Dominance, Being Dominated, Transitiveness and Equability}

Stakeholders or their representatives may give a different importance to objectives in a multi-objective problem but this is not the case with the three methods of MULTIMOORA. These three methods represent all possible methods with dimensionless measures in multi-objective optimization and one can not argue that one method is better than or is of more importance than the others.

\section{Dominance}

Absolute Dominance means that an alternative, solution or project is dominating in ranking all other alternatives, solutions or projects which are all being dominated. This absolute dominance shows as rankings for MULTIMOORA: (1-1-1).

General Dominance in two of the three methods with a $\mathrm{Pb} \mathrm{Pc} \mathrm{Pd}$ (P preferred to) is for instance of the form:

$$
\begin{aligned}
& \text { (d-a-a) is generally dominating (c-b-b), } \\
& \text { (a-d-a) is generally dominating (b-c-b), } \\
& \text { (a-a-d) is generally dominating (b-b-c), }
\end{aligned}
$$

and further on transitiveness plays fully. 


\section{Transitiveness}

If $\mathrm{a}$ dominates $\mathrm{b}$ and $\mathrm{b}$ dominates $\mathrm{c}$ than also $\mathrm{a}$ will dominate $\mathrm{c}$.

\section{Overall Dominance of one alternative on another}

For instance (a-a-a) is overall dominating (b-b-b) which is overall being dominated by (a-a-a).

\section{Equability}

Absolute Equability has the form: for instance (e-e-e) for 2 alternatives.

Partial Equability of 2 on 3 exists, e.g., (5-e-7) and (6-e-3).

\section{Circular Reasoning}

Despite all distinctions in classification some contradictions remain possible in a kind of Circular Reasoning.

We can cite the case of:

Object A (11-20-14) dominates generally object B (14-16-15).

Object B (14-16-15) dominates generally Object C (15-19-12), but Object C (15-1912) dominates generally Object A (11-20-14).

In such a case the same ranking is given to the three objects.

The same rules apply for the three methods of MULTIMOORA. with no significance coefficients proposed.

\subsection{Is the Theory of Dominance not Overlapping with Other Theories?}

Let us illustrate this question with the example: "how to choose a secretary?" Three choices are possible as explained in the Table 5.

Beside the Theory of Dominance can be discussed: (1) the Plurality Rule assisted with a kind of Lexicographic Method, (2) the Method of Correlation of Ranks.

\subsubsection{The Plurality Rule Assisted with a Kind of Lexicographic Method}

In 1785 Condorcet was not satisfied with the generally used form of voting. Starting from that view he examined the possibility of giving votes to different rankings of candidates, whereas the final decision was taken after the Plurality Rule, i.e., in favor of the candidate receiving the greatest number of votes for all its first places. A further elaboration would

Table 5

The choice of a secretary

\begin{tabular}{llll}
\hline Secretary & Typewriting & Friendly & Intelligent \\
\hline A & Extremely good (1) & Extremely friendly (1) & Extremely stupid (3) \\
B & Extremely bad (3) & Extremely unfriendly (3) & Extremely intelligent (1) \\
C & Good (2) & Friendly (2) & Quite intelligent (2) \\
\hline
\end{tabular}


lead to the Condorcet Paradox (Brauers, 2004a, pp. 118-119), later taken over by Arrow ${ }^{1}$. For Bordes and Tideman (1991) Arrow's General Possibility Arrow's Theorem (1963, p. 13, 15, 97), which is rather an Impossibility Theorem, is mainly based on the manipulation of candidacies in voting, for us alternatives. The result could be a reverse order.

Following the Plurality Rule secretary A is chosen with 2 first places. With a kind of Lexicographic method secretary B will rank second with one first place. In these methods secretary $\mathrm{C}$ will always take the last rank despite his or her satisfactory position in all fields.

6.3.2. The Method of Correlation of Ranks of Kendall (1948, p. 87)

Kendall ranks in an ascending order and according to the sum of ranks allotted to the individuals. In this way the following ranking is obtained: (1) A with 5 points; (2) $\mathrm{C}$ with 6 points; (3) B with 7 points.

The Theory of Dominance comes to the same results:

A (1-1-3) dominates C (2-2-2) and B (3-3-1)

C (2-2-2) dominates B (3-3-1).

However there is an essential difference in method. The similarity has to be considered as pure chance.

6.3.3. The Method of Correlation of Ranks Compared to the Theory of Dominance The method of correlation of ranks consists of totalizing ranks. Rank correlation was introduced first by psychologists such as Spearman $(1904,1906,1910)$ and later taken over by the statistician Kendall in 1948. He argues (Kendall, 1948, p. 1): "we shall often operate with these numbers as if they were the cardinals of ordinary arithmetic, adding them, subtracting them and even multiplying them", but he never gives a proof of this statement. In his later work this statement is dropped (Kendall and Gibbons, 1990).

In ordinal ranking 3 is farther away from 1 than 2 from 1, but Kendal (1948, p. 1) goes too far (Table 6).

For Kendal B is far away from A as it has 7 ranks before and A only 4, whereas it is not true cardinally.

In addition a supplemental notion, the statistical term of Correlation, is introduced. Suppose the statistical universe is just represented by two experts, for us it could be two methods. If they both rank in a same order different items to reach a certain goal, it is said that the correlation is perfect. However, perfect correlation is a rather exceptional situation. The problem is then posited: how in other situations correlation is measured. Therefore, the following Spearman's coefficient is used (Kendall 1948, p. 8):

$$
\rho=1-\frac{6 \sum D^{2}}{N\left(N^{2}-1\right)}
$$

where $D$ stands for the difference between paired ranks, and $N$ for the number of items ranked.

\footnotetext{
${ }^{1}$ In the 1963-edition of his book Arrow maintains that in the first edition of 1951 he was not aware of the work of Condorcet: "When I first studied the problem and developed the contradictions in the majority rule system, I was sure that this was no original discovery, although I had no explicit reference, and sought to express this knowledge by referring to the well known 'paradox of voting" (Arrow, 1963, p. 93).
} 
Table 6

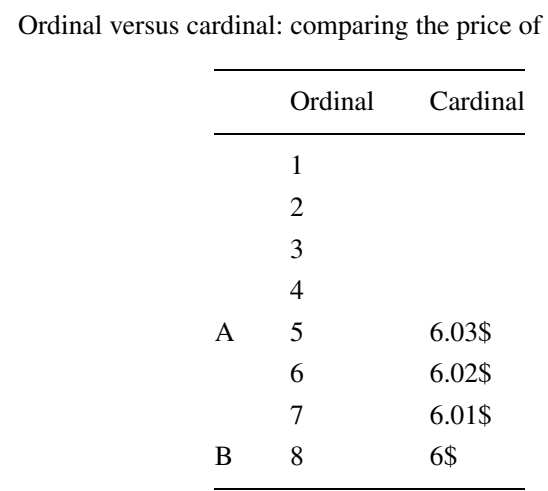

According to this formula, perfect correlation yields the coefficient of one. An acceptable correlation reaches the coefficient of one as much as possible. No correlation at all yields a coefficient of zero. If the series are exactly in reverse order, there will be a negative correlation of minus one, as shown in the following example (Table 7).

This table shows that the sum of ranks in the case of an ordinal scale has no sense. Correlation leads to:

$$
\rho=1-\frac{6 \times 112}{7 \times(49-1)}=-1 .
$$

However, as a sum of ranks is not allowed also a subtraction in the differences $D$ is not permitted.

The full multiplicative method with its huge outcomes illustrates the best the trend break between cardinal and ordinal numbers as shown in Table 8 .

In a usual arithmetical progression: $1,2,3,4,5, \ldots$ the distance from the rank 4 to 5 would be the same as from 3 to 4 which is certainly not the case here. In addition also all the other progressions fail to discover a trend break.

Table 7

Negative rank order correlations

\begin{tabular}{lllllr}
\hline Items & Expert 1 & Expert 2 & Sum of ranks & $D$ & $D^{2}$ \\
\hline 1 & 1 & 7 & 8 & -6 & 36 \\
2 & 2 & 6 & 8 & -4 & 16 \\
3 & 3 & 5 & 8 & -2 & 4 \\
4 & 4 & 4 & 8 & 0 & 0 \\
5 & 5 & 3 & 8 & 2 & 4 \\
6 & 6 & 2 & 8 & 4 & 16 \\
7 & 7 & 1 & 8 & 6 & 36 \\
\hline
\end{tabular}


Table 8

Ranking of scenarios for the Belgian regions by the Full-Multiplicative method at the year 1996

\begin{tabular}{lllc}
\hline & Scenario & Name & Total/100,000 (a) \\
\hline 1 & Scenario IX & Optimal Economic Policy in Wallonia and Brussels & 203,267 \\
2 & Scenario X & $\begin{array}{l}\text { Optimal Economic Policy in Wallonia and Brussels even } \\
\text { agreeing on the Partition of the National Public Debt }\end{array}$ & 196,306 \\
3 & Scenario VII & Flanders asks for the Partition of the National Public Debt & 164,515 \\
4 & Scenario VIII & No Solidarity at all & 158,881 \\
5 & Scenario II & Unfavorable Growth Rate for Flanders & 90 \\
6 & Scenario IV & An Unfavorable Growth Rate for Flanders and at that mo- & 87 \\
7 & Scenario III & ment asks also for the Partition of the National Public Debt & 54 \\
8 & Scenario I & The Average Belgian & 51 \\
9 & Scenario V & $\begin{array}{l}\text { Average Belgian but as compensation Flanders asks for } \\
\text { the Partition of the National Public Debt }\end{array}$ & 49 \\
10 & Scenario O & Status Quo & 43 \\
11 & Scenario VI & Flanders asks for the Partition of the National Public Debt & 42
\end{tabular}

(a) MAX. Private Income in BEF per Capita (Wallonia*Brussels*Flanders); MIN transfer payments in BEF per capita from Flanders to Wallonia; MIN in \% of Public Debt to GRP (Wallonia*Brussels*Flanders). Substitution of one BEF from transfer payments to private income in not possible.

Previously $1 \mathrm{BEF}=0.0247893$ Euro.

Source: Brauers, 1999, p. 15.

Contrary to the Method of Correlation of Ranks which mixes ordinal with cardinal scales in a not allowed manner, the Theory of Dominance operates and remains all the time in the ordinal sphere as demonstrated above.

\section{Conclusion}

For a researcher in multi-objective decision support systems the choice between many methods for multi-objective optimization is not very easy. We intended to assist the researcher with some guidelines for an effective choice. In order to distinguish the different multi-objective methods from each other we use a qualitative definition of robustness, with an outsider judging favorably on MULTIMOORA.

Multi-Objective Optimization by Ratio Analysis (MOORA), composed of two methods: ratio analysis and reference point theory starting from the previous found ratios, solves the difficult problem of normalization whereas the importance of the objectives is treated separately. If MOORA is joined with the Full Multiplicative Form for Multiple Objectives, also with the importance of the objectives treated separately, a total of three methods is formed under the name of MULTIMOORA, a mighty instrument for Multi-Optimization in a Well Being Society. MULTIMOORA, eventually joined with Delphi for giving importance to an objective, represents the most robust approach for multi-objective optimization up to now. 


\section{References}

Allen, R.G.D. (1957). Mathematical Economics. Macmillan, London.

Arrow, K.J. (1963). Social Choice and Individual Values. Yale University, New Haven.

Arrow, K.J. (1974). General economic equilibrium: purpose, analytic techniques. Collective Choice, American Economic Review, June, 253-272.

Bordes, G., Tideman, N. (1991). Independence of irrelevant alternatives in the theory of voting. Theory and Decision, 182-183.

Brans, J.P., Mareschal, B., Vincke, P. (1984). Prométhée: a new family of outranking methods in multicriteria analysis. In: Proceedings of the IFORS 84 Conference, Washington, pp. 408-421.

Brans, J.P., Mareschal, B., Vincke, P. (1986). How to select and how to rank projects: the PROMETHEE method. European Journal of Operational Research, 24(2), 228-238.

Brauers, W.K. (1999). Een optimaal economisch beleid voor België en zijn gewesten volgens de multipele effectiviteitsanalyse (An optimal economic policy for Belgium using a multi-objective analysis), Documentatieblad, Department of Finance of Belgium, Studie en Documentatiedienst, LIX, 5, 3-24.

Brauers, W.K. (2002). The multiplicative representation for multiple objectives optimization with an application for arms procurement. Naval Research Logistics, 49, 327-340.

Brauers, W.K. (2004a). Optimization Methods for a Stakeholder Society, a Revolution in Economic Thinking by Multi-Objective Optimization", Nonconvex Optimization and its Applications, Series Vol. 73. Kluwer Academic/Springer, Boston/Dordrecht/London.

Brauers, W.K. (2004b). Multi-objective optimization for facilities management. Journal of Business Economics and Management, 5(4), 173-182.

Brauers, W.K. (2004c). Multiobjective optimization (MOO) in privatization. Journal of Business Economics and Management, 5(2), 59-66.

Brauers, W.K. (2007). What is meant by normalization in decision making? International Journal of Management and Decision Making, 8(5/6), 445-460.

Brauers, W.K. (2008). Multi-objective decision making by reference point theory for a wellbeing economy. International Journal of Operations Research, 8, 89-104.

Brauers, W.K.M., Ginevicius, R. (2009). Robustness in regional development studies, the case of Lithuania. Journal of Business Economics and Management, 10(2), 121-140.

Brauers, W.K.M., Zavadskas, E.K. (2006). The MOORA method and its application to privatization in a transition economy. Control and Cybernetics, 35(2), 445-469.

Brauers, W.K., Zavadskas, E.K. (2010a). Is robustness really robust? Robustness from the point of view of Statistics and Econometrics with an application for multi-objective optimization. In: Multiple Criteria Decision Aiding. Nova Science, Inc. Hauppage, 17-42.

Brauers, W.K.M., Zavadskas E.K. (2010b). Project management by MULTIMOORA as an instrument for transition economies. Technological and Economic Development of Economy, 16(1), 5-24.

Brauers, W.K.M., Zavadskas E.K. (2010c). Robustness in the MULTIMOORA model, the case of Tanzania. Transformations in Business and Economy, 9(3), 67-83.

Brauers, W.K.M., Zavadskas, E.K. (2011). MULTIMOORA optimization used to decide on a bank loan to buy property. Technological and Economic Development of Economy, 17(1), 174-188.

Brauers, W.K.M., Balezentis, A., Balezentis, T. (2011). MULTIMOORA for the EU member states updated with fuzzy number theory. Technological and Economic Development of Economy, 17(2), 259-290.

Casella, G., Berger, R.L. 2002. Statistical Inference, 2nd edn. Thomson Learning, Pacific Grove.

Chakraborty, S. (2011). Applications of the MOORA method for decision making in manufacturing environment. International Journal Advanced Manufacturing Environment, 54(9-12), 1155-1166.

Churchman, C.W., Ackoff, R.L. (1954). An approximate measure of value. Operations Research, 2, 172-180.

Churchman, C.W., Ackoff, R.L., Arnoff, E.L. (1957). Introduction to Operations Research. Wiley, New York.

Condorcet, Marquis de (1785). Essai sur l'application de l'analyse à la probabilité des décisions rendues à la pluralité des voix. l'Imprimerie Royale, Paris.

De Jong, F.J. (1967). Dimensional Analysis for Economists. North-Holland, Amsterdam.

Gossen, H.H. (1853). Entwicklung der Gesetze des menschlichen Verkehrs und der daraus flieszenden Regeln für menschliches Handeln, 3 Aufl. Prager, Berlin, 1927.

Hays, W.L. (1974). Statistics for the Social Sciences. Holt, Rinehart and Winston, London.

Hoel, P.G. (1971). Elementary Statistics. Wiley, New York. 
Huber, P.J. (1969). Theorie de l'inférence statistique robuste. Les Presses de l'Universite de Montreal, Montreal.

Hwang, C.-L., Yoon, K. (1981). Multiple Attribute Decision Making, Methods and Applications, Lecture Notes in Economics and Mathematical Systems, Vol. 186. Springer, Berlin.

Intriligator, M.D. (1978). Econometric Models, Techniques and Applications. North Holland, Amsterdam.

Karlin, S., Studden, W.J. (1966). Tchebycheff Systems: With Applications in Analysis and Statistics. Interscience Publishers, New York.

Keeney, R.L. (1973). A decision analysis with multiple objectives: the Mexico City airport. The Bell Journal of Economics and Management Sciences, 4(1), 101-117.

Keeney, R.L., Raiffa, H. (1993). Decisions with Multiple Objectives. Preferences and Value Tradeoffs. Cambridge University Press, Cambridge.

Kendall, M.G. (1948). Rank Correlation Methods. Griffin, London.

Kendall, M.G., Gibbons, J.D. (1990). Rank Correlation Methods. Edward Arnold, London.

Kreps, D.M. (1990). Game Theory and Economic Modelling. Oxford University Press/Clarendon Press, Oxford.

MacCrimmon, K.R. (1968). Decision Making among Multiple Attribute Alternatives: A Survey and Consolidated Approach. RM-4823-ARPA. The Rand Corporation, Santa Monica.

Matyas, L., Sevestre, P. (1992). The Econometrics of Panel Data. Handbook of Theory and Applications, Advanced Studies in Theoretical and Applied Econometrics, Vol. 28. Kluwer Academic, Dordrecht.

Miller, D.W., Starr, M.K. (1969). Executive Decisions and Operations Research. Prentice-Hall, Englewood Cliffs, pp. 237-239.

Minkowsky, H. (1911). Gesammelte Abhandlungen. Teubner, Leipzig.

Minkowsky, H. (1896). Geometrie der Zahlen. Teubner, Leipzig.

Opricovic S., Tzeng G.-H. (2004). Compromise solution by MCDM methods: a comparative analysis of VIKOR and TOPSIS. European Journal of Operational Research, 156, 445-455.

Pareto, V. (1906). Manuale di Economia Politica, Translation revised by Pareto Himself, Manuel d'économie politique, 2nd edn., Paris, 1927.

Pigou A.C. (1920). The Economics of Welfare, 4th edn. Macmillan, London 1950 (1st ed. 1920).

Roy, B. (1968). Classement et choix en présence de points de vue multiples (la méthode Electre). Revue française d"informatique et de recherche opérationnelle, 2(8), 57-75.

Roy, B. (1977). Electre III. Rapport de recherché n 81. Sema, Paris.

Roy, B., Hugonnard, J.C. (1982). Classement des prolongements de lignes de métro en banlieue parisienne, Cahiers du CERO, 23, 153-171.

Roy, B., Bertier, P. (1971). La méthode Electre II, une méthode de classement en présence de critères multiples. Note de travail 142. Direction scientifique. Sema, Paris.

Roy, B., Benayoun, R., Sussman. B. (1966). ELECTRE. Société d'economie et de mathématique appliquées, Paris.

Saaty, T.L. (1988). The Analytic Hierarchy Process. Mcgraw-Hill, New York.

Schärlig, A. (1985). Décider sur plusieurs critères. Presses polytechniques romandes, Lausanne.

Schärlig, A. (1996). Pratiquer Electre et Prométhée: un complément à décider sur plusieurs critères, Vol. 11, Presses polytechniques et universitaires romandes, Lausanne.

Spearman, C. (1904). The proof and measurement of association between two things. American Journal of Psychology, 15, 72-101.

Spearman, C. (1906). A footrule for measuring correlation. British Journal of Psychology, 2, 89-108.

Spearman, C. (1910). Correlation calculated from faulty data. British Journal of Psychology, 3, 271-295.

Stigler, S., Newcomb, S., Daniell P. (1973). The history of robust estimation 1885-1920. Journal of the American Statistical Association, 68, 872-879.

Teekens, R., Koerts, J. (1972). Some statistical implications of the log transformation of multiplicative models. Econometrica, 40(5), 793-819.

Thomas, R.L. (1985). Introductory Econometrics. Longman, London.

UNIDO, United Nations Industrial Development Organization. (1978). Manual for the preparation of Industrial Feasibility Studies. United Nations, New York.

Vincke, P. (1999). Robust solutions and methods in decision aid. Journal of Multi-Criteria Decision Analysis, 181-871.

Wonnacott, R.J., Wonnacott, T.H. (1970). Econometrics. New York, Wiley. 
W.K.M. Brauers doctor honoris causa Vilnius Gediminas Technical University, was graduated as: $\mathrm{PhD}$ in economics (un. of Leuven), master of arts (in economics) of Columbia University (New York), master in economics, master in management and financial sciences, master in political and diplomatic sciences and bachelor in philosophy (all of the University of Leuven). He is professor ordinarius at the Faculty of Applied Economics of the University of Antwerp, honorary professor at the University of Leuven, the Belgian War College, the School of Military Administrators and the Antwerp Business School. He was a research fellow in several American institutions like Rand Corporation, the Institute for the Future, the Futures Group and extraordinary advisor to the Center for Economic Studies of the University of Leuven. He was consultant in the public sector, such as the Belgian Department of National Defense, the Department of Industry in Thailand, the project for the construction of a new port in Algeria (the port of Arzew) and in the private sector such as the International Seaport of Antwerp and in electrical works. He was chairman of the Board of Directors of Sorca ltd. Brussels, management consultants for developing countries, linked to the worldwide group of arcadis and chairman of the Board of Directors of Maresco ltd. Antwerp, marketing consultants. At the moment he is general manager of consulting, systems engineering consultants. Brauers is member of many international scientific organizations. His specialization covers: optimizing techniques with different objectives, forecasting techniques, input-output techniques and public sector economics such as for national defense and for regional sub-optimization. his scientific publications consist of seventeen books and several hundreds of articles and reports in english, dutch and french.

E.K. Zavadskas is head of Institute of Internet and Intellectual Technologies at Vilnius Gediminas Technical University, and head of the Department of Construction Technology and Management at Vilnius Gediminas Technical University, Vilnius, Lithuania. He has a $\mathrm{PhD}$ in building structures (1973) and Dr Sc (1987) in building technology and management. He is a member of the Lithuanian and several foreign academies of sciences. He is doctor honoris causa at Poznan, Saint-Petersburg, and Kiev universities. He is a member of international organizations and has been a member of steering and programme committees at many international conferences. E.K. Zavadskas is a member of editorial boards of several research journals. He is author and co-author of more than 400 papers and a number of monographs. Research interests are: building technology and management, decision-making theory, automation in design and decision support systems. 


\section{Daugiatikslès optimizacijos MULTIMOORA metodo stiprumas}

\section{Willem Karel M. BRAUERS, Edmundas Kazimieras ZAVADSKAS}

Daugiatikslè optimizacija iškelia skirtingus tikslus, kurie išsaugo tikslams būdingus mato vienetus. Santykių Sistemos (Ratio System) vidiniai sprendiniai suteikia galimybę naudoti bedimensius dydžius. Taip pat, Santykių Sistema (Ratio System) leidžia taikyti Atskaitos taško (Reference Point) metodiką. Sujungus abu metodus išvesta MOORA (daugiatikslis optimizavimas remiantis santykio analize) metodo teorija. Pasiekti dar tikslesnius rezultatus galima taikant pilnaja sandaugos formą (Full Multiplicative Form), kurią apjungia MULTIMOORA (MOORA plius pilnoji sandaugos forma) metodas. Išbandžius MULTIMOORA metodo stiprumą gaunami tikslūs rezultatai. 
